\title{
EFFICACY OF INCISAL PREPARATION DESIGNS ON THE FRACTURE RESISTANCE OF TWO CAD/CAM LAMINATE VENEERS
}

\author{
Eman Essam*, Inas T. Motawea ** and Heba E. Eltayeb ${ }^{* * *}$
}

\begin{abstract}
Statement of problem: Mechanical properties are cardinal for the long-term clinical success of laminate veneer restorations. The most common failure is fracture and debonding, in which unfavorable occlusion and articulation play an important role. Nonetheless, the effect of different incisal preparations on the behavior of veneers remains controversial.
\end{abstract}

Objective: The purpose of this study was to evaluate the fracture load of two different CAD/ CAM laminate veneer materials: resin nano-ceramic [lava ultimate] and lithium disilicate glass ceramic [IPS e-max CAD], with two different incisal preparation designs [butt-Joint and incisal overlap]; using both in-vitro and finite element analysis studies.

Materials and Methods: A total of 20 maxillary central incisors were used in this study. The samples were divided into two main groups $(n=10)$, according to the CAD/CAM material used. Ten laminate restorations were constructed for each group following the manufacturer's directions with the two preparation designs ( 5 samples each), then cemented on their corresponding teeth. Fracture load was recorded for each specimen using the universal testing machine. Meanwhile, Finite element analysis study was performed to assess the in-vitro observations.

Results: The results revealed that incisal overlap design with Lava ultimate laminate veneers recorded the highest mean fracture strength value $(395 \pm 37.18 \mathrm{~N})$. This was supported by the finite element results that showed that the incisal overlap design with lava ultimate laminate veneers had the lowest Von Mises stress (30.75 MPa).

Conclusions: Within the limitations of the present study, it was concluded that the butt-joint and incisal overlap designs demonstrated different mechanical behaviors with regard to the two different restorative materials. The incisal overlap design tolerated stresses better than the buttjoint design with both materials. Also, the incisal overlap design with resin nano-ceramic laminate veneers had the best stress distribution. Nevertheless, both types of CAD/CAM materials and different incisal preparation designs used could be considered strong enough to withstand the average anterior masticatory biting forces.

KEY WORDS: Preparation design; fracture resistance; Laminate veneer techniques; resin nano-ceramic; IPS e-max CAD.

\footnotetext{
* Assistant Professor of Fixed Prosthodontics, Faculty of Dental Medicine, Al-Azhar University, Egypt. ** Assistant Professor of Dental Materials, Faculty of Dental Medicine (Girls), Al-Azhar University. *** Lecturer of Dental Materials, Faculty of Dental Medicine ( Girls), Al-Azhar University.
} 


\section{INTRODUCTION}

Personal appearance is getting more and more important in society. A properly formed smile line and teeth that are aligned and contoured in accordance with this line are considered the most important factors that affect appearance. Orthodontic, periodontal and restorative operations are performed together or separately in patients who make this request. ${ }^{1}$ For many years, the most predictable and durable aesthetic correction of anterior teeth has been achieved by the preparation of full crowns. However, this approach is more invasive with substantial removal of large amounts of sound tooth structure and possible adverse effects on the adjacent pulp and periodontal tissues. Due to the growing patient demand for esthetic restorations and more conservative trends in restorative dentistry, the use of porcelain veneers has become a widespread, reliable and successful technique for restoring discolored, worn, malformed or fractured teeth.Laminate veneers are among the most beautiful and long-lasting of all dental restorations., ${ }^{2,3}$

CAD/CAM stands for computer aided design/ computer aided milling. Dr. Duret, Dr. Anderson and Dr. Mörmann have created dental CAD/CAM systems with the studies they have conducted. After these pioneer scientists, dental CAD/CAM systems have progressed rapidly and their scope of indications has grown. Today, laminate veneer, inlay, onlay, bridgeworks, structures of partial denture, personal implants, implant supported dentures and crowns can be made. In this system, prefabricated blocks are used for drilling. These blocks may be manufactured for various indications with various content such as ceramics, metal alloys, zirconium oxide and resin. ${ }^{1}$

A cumulative success rate of approximately $93 \%$ was reported after a 15-year retrospective clinical observation, ${ }^{4}$ and the relative success rate without minor alterations was recorded at $85 \%$ and $72 \%$ for two preparation designs in a 5-year prospective study. ${ }^{5}$ The most frequent failure associated with veneers was fracture and debonding, in which unfavorable occlusion and articulation play an important role. The incisal margin and cervical area were reported to be the most likely regions to fail. ${ }^{6-8}$ Therefore, the mechanical properties were important to long-term clinical success. No consensus has been reached regarding the geometric effect on the mechanical behavior of veneer. Four widely accepted designs are the 'window preparation,' which is limited in the labial surface and does not involve the incisal edge, the 'feather preparation,' which covers the entire labial surface with a thin layer up to the incisal edge, and the 'incisal overlap preparation,' which involves the preparation of the incisal edge. The incisal overlap preparation can be divided into 2 categories, depending on the configuration of the incisal area, either with a palatal chamfer or only an incisal reduction (butt-joint)..$^{9,10}$

Analyzing stress distribution in teeth or restorations is difficult because of the different materials and complex geometries involved. ${ }^{11}$ One of the most powerful and effective tools is Finite element analysis (FEA). ${ }^{12}$ Zarone et $\mathrm{al}^{11}$ and Sorrentino et $\mathrm{a}^{13}$ successfully applied 3-dimensional (3D) FEA to incisal overlapped veneer restorations, but only the type with a palatal chamfer. Magne and Douglas ${ }^{14}$ conducted a 2-dimensional FEA on the incisal preparations both with a palatal chamfer and with a butt joint. However, the veneer restoration was a 3D structure, and, although the 2- dimensional model considered the most important buccolingual plane, considerable information was not included.

Hence, there is no agreement regarding the use of any design of the different preparation designs. Consequently, this study was undertaken to evaluate the effect of the two different incisal preparations, namely the butt-joint and incisal overlap designs; and two different CAD/CAM materials (lithium disilicate glass ceramic and resin nano-ceramic) on the fracture resistance of laminate veneers. In-vitro 
and finite element analysis studies will be collated to appraise those variables. It was hypothesized that there would be no significant differences between the investigated parameters.

\section{MATERIALS AND METHODS}

Twenty human maxillary central incisor teeth with no decay or restorations, extracted for periodontal reasons, were selected. Dental plaque, calculus, and periodontal fibers were removed. The specimens were divided into 2 main groups: 10 teeth restored with laminate veneers fabricated from IPS e-max CAD Lithium disilicate glass ceramic blocks (Ivoclar Vivadent AG) "group I". While the other 10 samples were restored with laminate veneers fabricated from Lava Ultimate Resin nano-ceramic blocks (3M ESPE Dental products) “group II”. Each group was subdivided into 2 subgroups $(\mathrm{n}=5)$ : buttjoint and incisal overlap preparation designs.

The teeth were mounted individually in special molds $(2.5 \mathrm{~cm}$ height $\times 2 \mathrm{~cm}$ diameter) with epoxy resin, with the long axis parallel to the center of the mold. Each tooth was suspended in the middle of the mold using Ney Surveyor (Lukadent Gmbh, Germany) to ensure vertical positioning of the tooth inside the mold as follows: an analyzing metal rod of the Ney Surveyor was fixed to the center of the incisal edge of each tooth and along its long axis using sticky wax, and then it was attached to the vertically moving arm of the surveyor. When the axis of the tooth was positioned correctly, epoxy resin was poured into the mold. All specimens were embedded up to $2 \mathrm{~mm}$ below the CEJ to simulate the natural biologic width.

Silicone putty impressions (Express STD, 3M ESPE) were done on all of the teeth specimens before their preparation. These impressions were used as templates to evaluate the amount of tooth reduction. Standardized preparations were done in the labial surface of all teeth. The reduction was guided by a 3-wheel diamond depth cutter. By using this standardized diameter instrument, equal preparations were approximately of about $0.5 \mathrm{~mm}$ depth, the preparations were completed using tapered stones with round end. For the buttjoint preparation: teeth were prepared with a 2 $\mathrm{mm}$ incisal reduction without palatal chamfer, and for the incisal overlap preparation: teeth were prepared with a $2 \mathrm{~mm}$ incisal reduction and $1 \mathrm{~mm}$ height palatal chamfer. Any sharp angles that might serve as a focal point for stress concentration were removed, particularly at the junction of the incisal line and point angles to both the labial and lingual surfaces.

Labial reduction was $0.5 \mathrm{~mm}$ to ensure that the whole preparation remained in enamel. The reduction was carried out at two different planes to follow the contour of the labial surface. This was done using a tapered diamond stone with round end. The cervical margin was placed $1 \mathrm{~mm}$ coronal to the cemento-enamel junction. A chamfer finish line was insured all around the preparation margin; it was checked for uniformity and continuity. The thickness of the finish line was checked using a digital caliper (S235,Sylvac,Switzerland). Proximal reduction was done using the tapered diamond stone with round end. The end of the proximal reduction was placed just beyond the mesio-labial and disto-labial line angles. The entire reduction was completed within the enamel.

For restoration construction; to obtain a three dimensional image for each specimen on the computer screen, the following steps were performed: The teeth were fixed to the tray of the scanner using specific clay. Then the prepared teeth were sprayed using light reflecting powder to be scanned using the Jscan scanner for taking the optical impression. The scanning process of the tooth was completed after 14 minutes and a digital impression was captured for the tooth. Then the captured picture was saved in the occlusion catalogue of the software. An automatic margin finder is used for preparation margin detection. Ceramic laminate veneer thickness was checked by the software in order to standardize the thickness 
of all the samples and then next icon was clicked so that the finished restoration was displayed in the milling situation. The IPS e-max CAD blocks were fixed to their place in the Roland milling machine (Roland DG Corporation, Japan) and the preview window was activated to start the milling process. The type and size of the block was selected in the (manufacturer) window box.DWX-50 axis, auto tool changer was then activated. In case of lava ultimate restoration, the lava ultimate block was also fixed in its place in the Roland machine by special attachment. After completion of the milling process, the veneers were separated manually from either IPS e-max CAD or lava ultimate blocks with a diamond cutting instrument. According to manufacturer's instructions, the Lava Ultimate Restorative veneers didn't require any further firing or glazing. The IPS e-max CAD ceramic Laminate veneers were placed on a firing pad and positioned on a honey comb firing tray then inserted into the Programat P300 furnace (Ivoclar Vivadent, Schaan,Liechtenstein), the starting temperature was $403{ }^{\circ} \mathrm{C}$ and increased at a rate of $90{ }^{\circ} \mathrm{C} / \mathrm{min}$ until $840{ }^{\circ} \mathrm{C}$ and hold for 7 minutes. Then all laminate veneers were checked for complete seating on their corresponding teeth.

Surface treatment of the laminate veneers was done; the fitting surfaces were etched using 5\% hydrofluoric acid gel (IPS Ceramic Refill) according to the manufacturer instructions. The laminate veneers were then washed thoroughly with air/water spray for 30 seconds. They were dried using oil-free compressed air. All laminate veneers were then primed for resin onto their intaglio surface using a silane coupling agent (Monobond-S) for 60 seconds according to the manufacturer instructions, then airdried before cementation.

The enamel of the prepared surfaces of all teeth samples was acid etched using $37 \%$ phosphoric acid etching gel (Total-Etch) for 30 seconds, rinsed by air/water spray for another 20 seconds, then dried with air spray. Adper Single bond 2 adhesive was applied for 20 seconds with a micro-brush on the etched enamel surfaces of all teeth. The adhesive was thinned by gentle air spray.

Cementation of the restoration was then performed; a dual cure composite resin luting agent (Rely x ultimate) was used. A thin layer of the resin cement was applied to the center of the intaglio surface of the veneer. A light pressure was exerted on the restoration. The excess cement was carefully removed. Light curing was performed 20 seconds for each surface according to manufacturer's instructions using a light curing unit (GNATUS, Optilight). All samples were stored for $48 \mathrm{hrs}$ in saline solution at room temperature 37 Co until fracture load testing. Samples were then individually mounted on a computer controlled materials testing machine (Model 3345; Instron Industrial Products, Norwood, MA, USA) with a load cell of $5 \mathrm{kN}$ and data were recorded using computer software (Instron Blue hill Lite Software). Samples were secured to the lower fixed compartment of testing machine by tightening screws. (Fig. 1).

Fracture test was done by compressive mode of load applied at $135^{\circ}$ angle (through housing the sample in specially designed $45^{\circ}$ angle jig) using a metallic rod with flat tip ( $5 \mathrm{~mm}$ diameter) attached to the upper movable compartment of testing machine traveling at cross-head speed of $1 \mathrm{~mm} / \mathrm{min}$ placed incisally with tin foil sheet in-between to achieve homogenous stress distribution and minimization of the transmission of local force peaks. The load

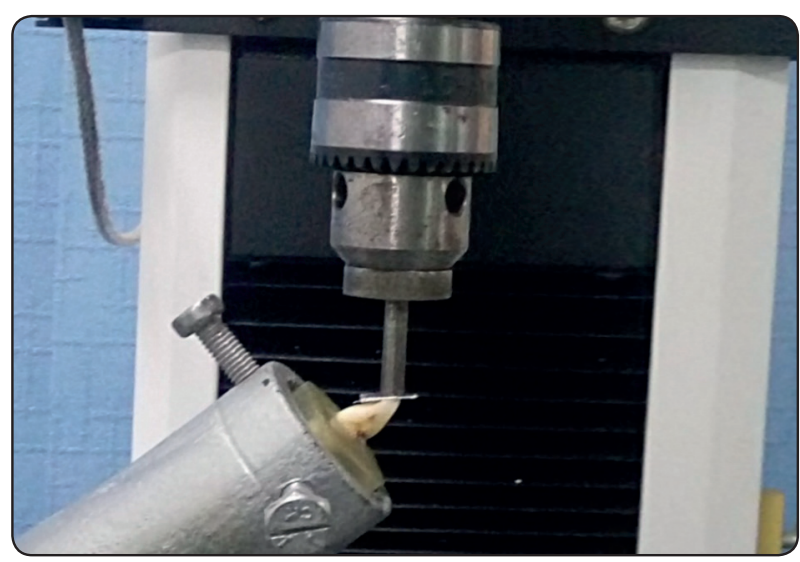

Fig. (1): Load application during fracture strength test. 
at failure was manifested by an audible crack and confirmed by a sharp drop at load-deflection curve recorded using computer software (Instron ${ }^{\circledR}$ Bluehill Lite Software).

\section{Finite Element Analysis}

An extracted human maxillary central incisor was used to develop the 3D finite element model. With cone-beam computed tomography (CT) (3D Accuitomo XYZ Slice View Tomograph; J. Morita Mfg Corp), with slicing interval space of $0.25 \mathrm{~mm}$. The scanned profiles were assembled in a 3D solid model with software (Mimics 10.01; Materialise Group; Rapidform 2004; Inus Technology Inc)) which exported a STL file of 803 vertices and 1598 faces to CAD software (Solidworks 2014) to be remodeled and prepared for FEA software (Cosmos).

Enamel and dentin were included in the solid model. A second modeling step was performed to obtain the veneer restored incisors. Two different types were tested: the butt joint design and the incisal overlap design. The solid model was modified by simulating a clinical preparation protocol (average $0.5-\mathrm{mm}$ buccal and proximal reduction, cervical margin placed $1.0 \mathrm{~mm}$ coronal to the cementoenamel junction) and chamfer made for all finish lines. The removed part of the crown was assumed to be the veneer; a cement layer with a thickness of $0.1 \mathrm{~mm}$ was built on the inner surface of the veneer. Two different incisal designs were formed; one was a $2 \mathrm{~mm}$ incisal reduction without a palatal chamfer (butt-joint design) and the other was a $2 \mathrm{~mm}$ incisal reduction with a $1 \mathrm{~mm}$ height palatal chamfer (incisal overlap design).

Two meshes were created with tetrahedral elements (Fig. 2); one mesh for the incisal overlap design with 26308 nodes and 14455elements, another mesh for the butt-joint design 13810 nodes and 7599 elements. The mesh is refined in order to present higher density in the important regions for this study. The accuracy of this model was checked by convergence tests. Different material properties ${ }^{15}$ (elastic modulus and Poisson ratio) are illustrated in Table (I). The following assumptions were made: the complete bonding between the veneer, cement layer, and tooth was considered; the restriction type between the cement layer, tooth structure, and periodontal ligament was tied; all materials were assumed to be elastic and isotropic.

A $100 \mathrm{~N}$ load was applied on the palatal surface of the incisal edge at angles of 45 degrees with the incisor longitudinal axis. A structural linear static analysis had been performed to evaluate the stress distribution in the critical regions. The complex stress states and stress redistribution at the interfaces between the veneer, cement, and tooth structure were analyzed by maximum principle stresses or the Von Mises criteria. Four tested models were formed with different materials and incisal designs.

TABLE (1) Mechanical properties of the materials

\begin{tabular}{|l|c|c|}
\hline \multicolumn{1}{|c|}{ Materials and Tissues } & $\begin{array}{c}\text { Elastic Modulus } \\
(\mathrm{MPa})\end{array}$ & $\begin{array}{c}\text { Poisson } \\
\text { Ratio }\end{array}$ \\
\hline Enamel & 84100 & 0.33 \\
\hline Dentin & 18600 & 0.32 \\
\hline Resin cement & 6000 & 0.30 \\
\hline Lava ultimate & 95000 & 0.30 \\
\hline IPS e-max CAD & 12800 & 0.30 \\
\hline
\end{tabular}

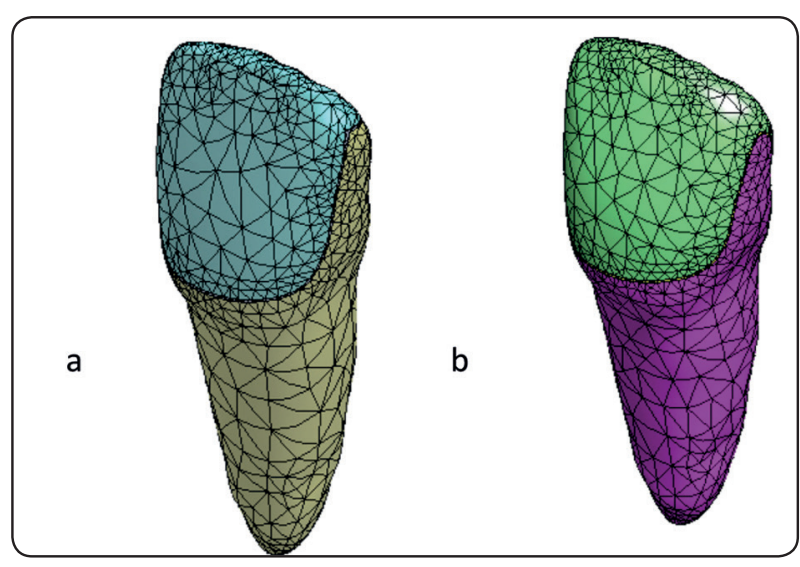

Fig. (2) a) Mesh of the Butt-join design, b) mesh of the incisal overlap design 


\section{Statistical analysis}

Data were collected, revised, coded and entered to the Statistical Package for Social Science (IBM SPSS) version 20. The quantitative data were presented as mean, standard deviations and ranges when their distribution found parametric. The comparison between two independent groups with quantitative data and parametric distribution was done by using Independent t-test while comparison between paired groups was done using Paired t-test. The confidence interval was set to $95 \%$ and the margin of error accepted was set to $5 \%$. So, the p-value was considered significant as the following: $P>0.05$ : Non significant, $\mathrm{P}<0.05$ : Significant and $\mathrm{P}<0.01$ : Highly significant.

\section{RESULTS}

Fracture strength results (Mean \pm SD) of incisal overlap and butt-joint designs with different materials are summarized in table (2) and graphically represented in figure (3). There was a significant difference in the mean fracture resistance values between the incisal overlap design and the butt-joint design with the studied CAD/ CAM materials $(\mathrm{P}<0.001)$. Incisal overlap design with Lava ultimate laminate veneers recorded the highest mean fracture strength value $(395 \pm 37.18$ N). Meanwhile, butt-joint design with IPS e-max CAD laminate veneers showed the lowest mean fracture strength value $(322.5 \pm 21.5 \mathrm{~N})$.

Regarding the incisal overlap design, there was no significant difference in the mean fracture resistance values between Lava ultimate and IPS e-max CAD laminate veneers ( $\mathrm{P}=0.002)$. However, there was a significant difference in the mean fracture resistance values between Lava ultimate and IPS e-max CAD laminate veneers concerning the butt-joint design ( $\mathrm{P}=0.763)$.
TABLE (2) Mean and Standard Deviation of the fracture strength of incisal overlap and butt-joint designs with the two different $\mathrm{CAD} / \mathrm{CAM}$ materials

\begin{tabular}{|l|c|c|c|c|}
\hline & $\begin{array}{c}\text { Incisal } \\
\text { overlap }\end{array}$ & $\begin{array}{c}\text { Butt- } \\
\text { joint }\end{array}$ & $\begin{array}{l}\text { Independent } \\
\text { t-test }\end{array}$ & p-value \\
\hline Lava ultimate & $395 \pm$ & $324.9 \pm$ & 6.693 & $<0.001$ \\
& 37.18 & 28.49 & & \\
\hline IPS e-max & $365.4 \pm$ & $322.5 \pm$ & 6.965 & $<0.001$ \\
CAD & 17.65 & 21.15 & & \\
\hline Paired t-test & 3.216 & 0.302 & & \\
\hline P-value & 0.002 & 0.763 & & \\
\hline
\end{tabular}

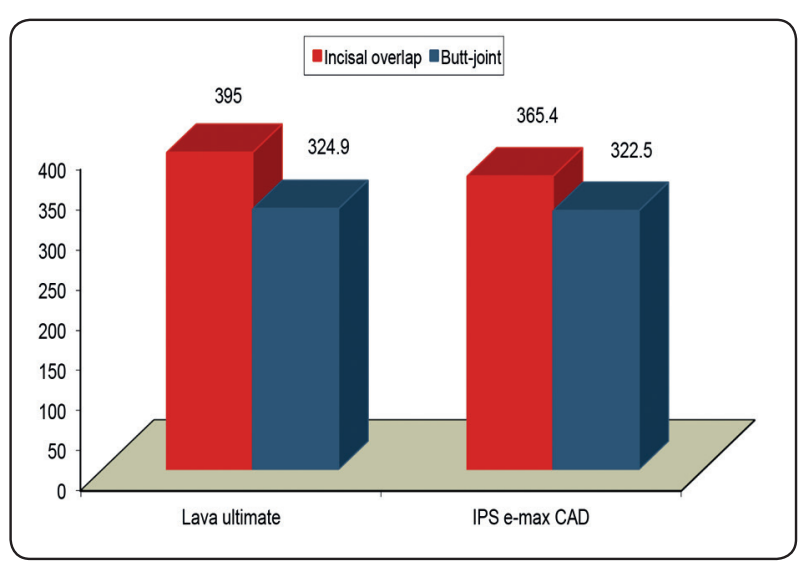

Fig. (3) Bar chart showing mean fracture strength values of incisal overlap and butt-joint designs with the two different CAD/CAM materials

Finite element analysis results are presented in stress/strain diagrams (figures 4,5,6,7), with the stress distribution for qualitative evaluation and in numeric values of the stress peaks for quantitative evaluation. In the four models stress concentration was observed in two locations, one in the mid third of the incisal margin, and the other in the mid third of the labial cervical area. The incisal overlap design with lava ultimate laminate veneers model showed the lowest Von Mises stress (30.75 MPa) and more uniform stress distribution especially in the veneer layer. However, the highest Von Mises stress were observed in the butt-joint design with IPS e-max CAD model (32.64 MPa). 


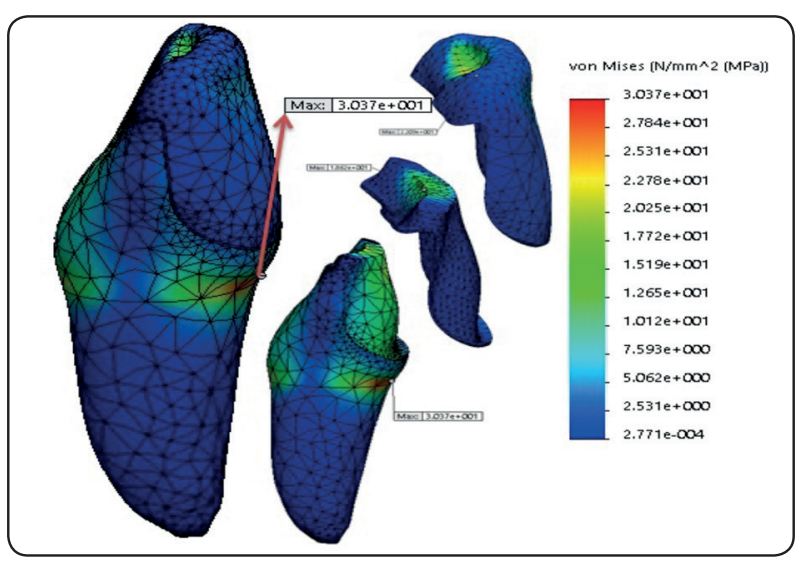

Fig. (4) Stress distribution in incisal overlap with lava ultimate model showing stress distribution in the tooth, cement layer, and ceramic veneer.

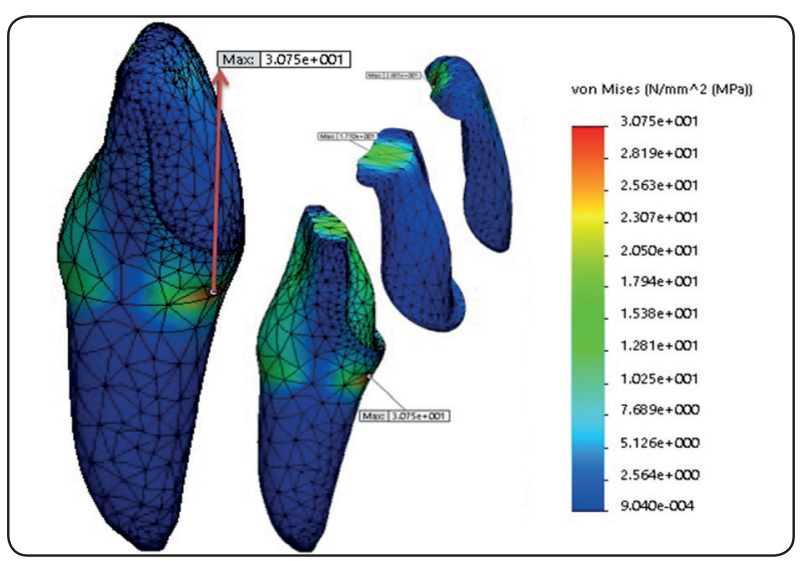

Fig. (6) Stress distribution in Butt-joint with lava ultimate model showing stress distribution in the tooth, cement layer, and ceramic veneer

\section{DISCUSSION}

Fracture resistance test is one of the stress tests recommended by ISO. It is recommended as a simple, precise and reliable method. Spheres, bars or bar shaped fracture tips may be used for fracture resistance tests. ${ }^{16}$ In a study conducted by Lin et al, ${ }^{17}$ it was proven that the fracture tip being applied from the edge with an angle of $135^{\circ}$, recreates the force laminate veneers are subjected to in the mouth.

Regarding the design of the preparation, basic types have been described: the window, the buttjoint, and the incisal overlapped preparation. ${ }^{18}$ As far as the thickness of preparation is concerned,

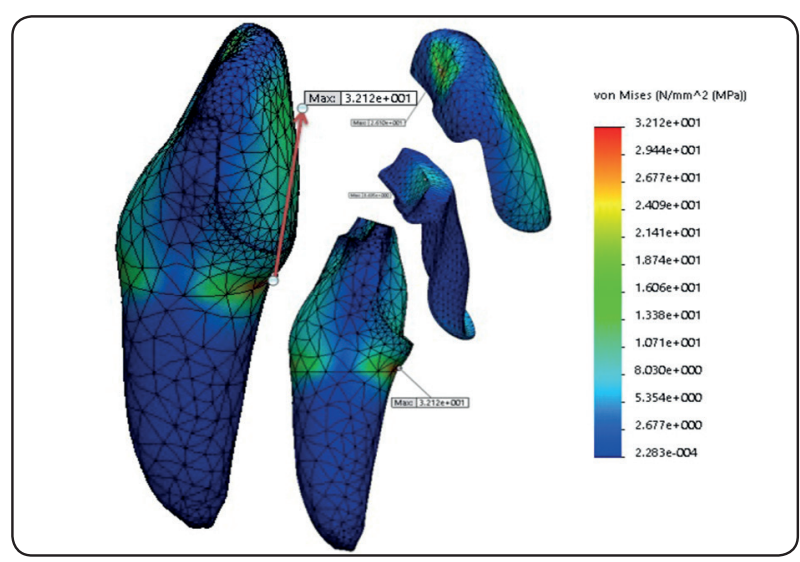

Fig. (5) Stress distribution in incisal overlap with IPS e-max model showing stress distribution in the tooth, cement layer, and ceramic veneer

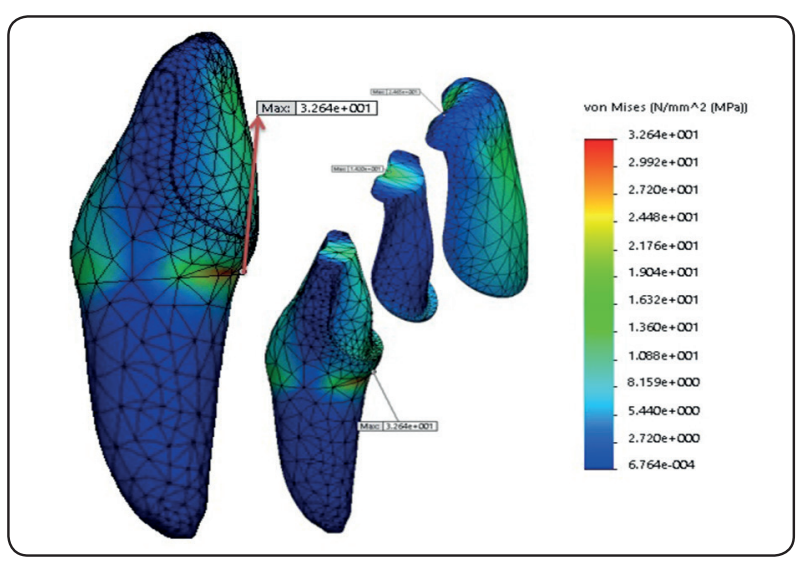

Fig. (7) Stress distribution in Butt-joint with IPS e-max model showing stress distribution in the tooth, cement layer, and ceramic veneer

the early concepts suggested minimal or no tooth preparation. Nevertheless, current beliefs support removal of varying amount of tooth structure, especially when mild malposition correction is aimed. ${ }^{6}$ One of the controversial topics regarding laminate veneers is the geometry of preparation. In the present study, human central incisor teeth were selected for specimen fabrication to mimic the natural conditions as they have flat labio-lingual width, and they are the most commonly restored teeth with laminate veneers. ${ }^{9}$ Regarding the depth of the preparations, standardized labial reduction was done $(0.5 \mathrm{~mm})$, to ensure the whole preparation confined into enamel. This allows better bonding, 
higher strength, less leakage, and excellent color matching without overcontouring. ${ }^{19}$

Theoretically, veneers should be subjected to minimal occlusal load and only used to restore esthetics, not function. ${ }^{20}$ However, Friedman ${ }^{21}$ held a different opinion and argued that veneers with appropriate incisal length could also provide valid anterior guidance. As a result, identifying factors that could be used to improve the mechanical behavior of veneers is important, especially the most appropriate preparation design. Magne et $\mathrm{al}^{22}$ observed no difference in survival between the butt-joint incisal configuration and the incisal preparation with a palatal chamfer at a 4.5 -year recall. In a 5-year prospective study, Guess and Stappert ${ }^{5}$ reported no significant difference in either survival rate or relative success rate between the two preparation designs.

However, incisal overlap cutting technique is recommended by many scientists, which include a section of the palatinal edge, which is aesthetically satisfactory as it provides better imitation of teeth and increases the resistance of the incisal edge to occlusal forces. ${ }^{23}$ Meijering et $\mathrm{al}^{24}$ have shown that the preparation type of the incisal edge is not related to the success of restoration, in a clinical study conducted for a term of 2.5 years. Troedson et $\mathrm{al}^{25}$ have reported that the direction of the chewing force on teeth is more significant for the success of restoration than the type of preparation.

A palatal chamfer was believed by Sheets and Taniguchi to be necessary to strengthen ceramic veneers. ${ }^{26}$ Stappert et al ${ }^{19}$ demonstrated no significant difference between the two designs. Evidence from a 2-dimensional finite element analysis (FEA), however, also showed no difference in stress distribution between preparations with a butt joint and with a palatal minichamfer. ${ }^{14}$

In a study concerning the photo elasticity of porcelain laminate veneers, Highton et al have reported that laminate veneers produced using the incisal overlap cutting technique dispense force more effectively and have higher fracture resistance when compared to natural teeth. ${ }^{27}$

In light of the findings of the present study, we are also able to say that incisal overlap preparation increases resistance to fracture in laminate veneers (table 2).

The current study showed that the incisal overlap design with lava ultimate laminate veneers had the lowest Von Mises stress (30.75 MPa) and more uniform stress distribution especially in the veneer layer. Lava Ultimate blocks have $80 \%$ nanoceramic filling in UDMA resin and thus they have an elastic structure compared to the porcelain containing materials; moreover, lava ultimate has low modulus of elasticity near to that of dentin..$^{28}$

In veneers produced using computer supported nano ceramic blocks, the highest values were obtained with incisal overlap cuts. In light of these data, we can state that incisal overlap cuts, which are claimed to distribute the stress most efficiently, have proven their success. ${ }^{6,29}$ Incisal overlap laminate veneer technique, which has provided the highest fracture resistance values, transmitted the force to hard dental tissue and the fractures were mainly observed at the cervical region of the teeth. Restorations produced using the CAD/CAM system, with the same cutting technique, have similar fracture resistance, however, they have proven to protect the hard dental tissue and were broken adhesively. Thus, the force absorbing effect of cement material is also proven. ${ }^{1}$

Previous 3D-FEA studies reported that the palatal chamfer and incisal area were stress concentrated. ${ }^{11,13}$ However, in this study, stress concentration was observed in the labial cervical third, which has not been previously reported. This was probably due to the modeling process. In vitro mechanical experiments showed that failure in the form of fracture or debonding could be expected at the incisal margin and labial cervical area. ${ }^{6,7}$ Stappert et al ${ }^{8}$ also observed that specimens fractured at root level un- 
der load after aging in a chewing simulator, a result in accordance with the stress concentration of the tooth structure in this study. Because the viscoelasticity of the periodontal ligament was not considered, stresses in the cervical areas of the tooth might be absorbed in the clinical situation.

A palatal finish line on a flat surface might be better reproduced, which makes it easier for technicians to fabricate the veneers. Moreover, insertion of veneers could be easier for clinicians.

The preparation of a palatal chamfer also increased the volume of the veneer, as a result, a larger restoration might distribute stress more uniformly. Castelnuovo et $\mathrm{al}^{6}$ observed that the strength of a butt-joint design with 2-mm incisal reduction was significantly higher than that of an incisal overlap design with 1-mm incisal reduction because of the thickness of the incisal ceramic. It was stated that further study is needed to analyze the butt-joint design with more incisal and proximal reduction. Based on the present results, incisal overlap design might be a better choice for CAD/CAM veneers because it has a lower maximum principle stress and a more uniform stress distribution in the cement layer. Those findings are in accordance with another two recent studies held by Li et al ${ }^{30}$ and Jankar et al. ${ }^{31}$

Although some researchers 9,32 used gum resin of different impression materials as a simulation of periodontal ligament in their studies. It was not used in this study because the progressive load applied on the coronal portion of the embedded tooth would not have been mitigated by the interposition of a softer medium between the root of the tooth and the surrounding epoxy resin. ${ }^{6,33}$

The average masticatory forces in the anterior region vary between $155 \mathrm{~N}$ and $200 \mathrm{~N} .^{7,34}$

The results of the current study indicated that both types of CAD/CAM materials and the different incisal preparation designs of laminate veneers used could be considered strong enough to withstand anterior forces. The null hypothesis was rejected as the two incisal preparations, namely the butt-joint design and incisal overlap design demonstrated different mechanical behaviors with the two different restorative materials.

\section{CONCLUSION}

Within the limitations of the present study, the following conclusions were drawn:

1. The butt-joint and incisal overlap designs demonstrated different mechanical behaviors with regard to the two different restorative materials.

2. The incisal overlap design tolerated stresses better than the butt-joint design with both materials.

3. The incisal overlap design with resin nano-ceramic laminate veneers had the best stress distribution.

4. Both types of CAD/CAM materials and the different incisal preparation designs used could be considered strong enough to withstand the average anterior masticatory biting forces.

\section{REFERENCES}

1. Duzyol M, Duzyol E, Seven N. Fracture Resistance of Laminate Veneers Made with Different Cutting and Preparation Techniques. I J D S R 2016; 4: 42-48.

2. Christensen G. Facing the challenges of ceramic veneers. J Am Dent Assoc 2006; 137: 661-664.

3. Peumans M, Van Meerbeek B, Lambrechts P, Vanherle G. Review Porcelain veneers: a review of literature. J Dent 2000; 28: 163-177.

4. Friedman MJ. A 15-year review of porcelain laminate veneers a clinician's observations. CompendContin Educ Dent 1998;19:625-636.

5. Guess PC, Stappert CFJ. Midterm results of a 5-year prospective clinical investigation of extended ceramic veneers. Dent Mater 2008;24:804-813.

6. Castelnuovo J, Tjan AHL, Phillips K, Nicholls JI, Kois JC. Fracture load and mode of failure of ceramic veneers with different preparations. J Prosthet Dent 2000;83:171-180.

7. Hahn P, Gustav M, Hellwig E. An in vitro assessment 
of the strength of porcelain veneers. J Oral Rehabil 2000;27:1024-1029.

8. Stappert CFJ, Stathopoulou N, Gerds T, Strub JR. Survival rate and fracture strength of maxillary incisors, restored with different kinds of full veneers. J Oral Rehabil 2005;32:266-272.

9. Zarone F, Epifania E, Leone G, Sorrentino R, Ferrari M. Dynamometric assessment of porcelain veneers related to tooth preparations: a comparison between two techniques. J Prosthet Dent 2006;95: 354-363.

10. Walls AWG, Steele JG, Wassell RW. Crowns and other extra-coronal restorations: porcelain laminate veneers. $\mathrm{Br}$ Dent J 2002;193: 73-76, 79-82.

11. Zarone F, Apicella D, Sorrentino R, Ferro V, Aversa R, Apicella A. Influence of preparation designs on stress distribution in maxillary central incisors restored by means of alumina porcelain: a 3-D finite element analysis. Dent Mater 2005;21:1178-1188.

12. Ausiello P, Apicella A, Davidson CL, Rengo S. 3D-finite element analyses of cusp movements in a human upper premolar, restored with adhesive resin-based composites. J Biomech 2001;34:1269-1277.

13. Sorrentino R, Apicella D, Riccio C, Gherlone E, Zarone F, Aversa R. Nonlinear viscoelastic finite element analysis of different porcelain veneers configuration. J Biomed Mater Res B Appl Biomater 2009;91:727-736.

14. Magne P, Douglas WH. Design optimization and evolution of bonded ceramics for the anterior dentition a finiteelement analysis. Quintessence Int 1999;30:661-672.

15. Zarone F, Apicella D, Sorrentino R, Ferro V, Aversa R, Apicella A. Influence of preparation designs on stress distribution in maxillary central incisors restored by means of alumina porcelain: a 3-D finite element analysis. Dent Mater 2005;21:1178-1188.

16. Plengsombut K, Brewer JD, Monaco EA, Davis EL. Effect of two connector designs on the fracture resistance of allceramic core materials for fixed dental prostheses. J Prosthet Dent 2009;101:166-173.

17. Lin TM, Liu PR, Ramp LC, Essig ME, Givan DA, Pan YH. Fracture resistance and marginal discrepancy of porcelain laminate veneers influenced by preparation design and restorative material in vitro. J Dent 2012;40:202-209.

18. Smales R., Etemadi S. Long-term survival of porcelain laminate veneers using two preparation designs: A retrospective study. Int J Prosthodont. 2004; 17: 323-326.

19. Stappert C, Ozden U, Gerds T, Strub J. Longevity and failure load of ceramic veneers with different preparation designs after exposure to masticatory simulation. J Prosthet Dent. 2005; 94: 132-139.
20. Toh CG, Setcos JC, Weinstein AR. Indirect dental laminate veneers an overview. J Dent 1987;15:117-124.

21. Friedman M. Multiple potential of etched porcelain laminate veneers. J Am Dent Assoc 1987:83E-87E.

22. Magne P, Perroud R, Hodges JS, Belser UC. Clinical performance of novel-design porcelain veneers for the recovery of coronal volume and length. Int J Periodontics Restorative Dent 2000;20:441-457.

23. Seymour KG, Samarawickrama DYD, Zou L. Tooth preparation for porcelain veneers--which technique do I use? Br Dent J 2002;192:1p.

24. Meijering AC, Creugers NH, Roeters FJ, Mulder J. Survival of three types of veneer restorations in a clinical trial: a 2.5-year interim evaluation. J Dent 1998;26:563-568.

25. Troedson M, Derand T. Effect of margin design, cement polymerization, and angle of loading on stress in porcelain veneers. J Prosthet Dent 1999;82:518-524.

26. Sheets CG, Taniguchi T. Advantages and limitations in the use of porcelain veneer restorations. J Prosthet Dent 1990;64: 406-11.

27. Shetty A, Kaiwar A, Shubhashini N, Ashwini P, Naveen D, Adarsha M. Survival rates of porcelain laminate restoration based on different incisal preparation designs: An analysis. JCD 2011;14:10-15.

28. Luhrs AK, Pongprueksa P, De Munck J, Geurtsen W, Van Meerbeek B. Curing mode affects bond strength of adhesively luted composite CAD/CAM restorations to dentin. Dent Mater 2014;30:281-291.

29. Pascotto RC, Benetti AR. The clinical microscope and direct composite veneer. Oper Dent 2010;35:246-249.

30. Li Z, Yang Z, Zuo L, Meng Y. A three-dimensional finite element study on anterior laminate veneers with different incisal preparations. J Prosthet Dent 2014;112(2): 325-333.

31. Jankar AS, Kale Y, Kangane S, Ambekar A, Sinha M, Chaware S. Comparative evaluation of fracture resistance of Ceramic Veneer with three different incisal design preparations - An In-vitro Study. J Int Oral Health. 2014; 6(1): 48-54.

32. Seymour K, Cherukara G, Samarawickrama D. Stresses within porcelain veneers and the composite lute using different preparation designs. J Prosthod 2001; 10: 16-21.

33. Turkaslan S, Tezvergil-Mutluay A, Bagis B, Shinya A, Vallittu P. Effect of intermediate fiber layer on the fracture load and mode of failure mode of maxillary incisors restored with laminate veneers. Dent Mater J 2008; 27; 61-68.

34. Gresnigt M, Ozcan M. Fracture strength of direct versus indirect laminates with and without fiber application at the cementation interface. Dent Mater 2007; 23: 927-933. 